\title{
Using Content, Context, and Process to Manage University Cutbacks
}

\author{
CYNTHIA HARDY*
}

\begin{abstract}
Funding and enrolment problems have led to recommendations for more strategic planning in universities. The traditional model of strategy making may not be appropriate, however, because it focusses on the content of strategies and ignores other elements in the strategy making process. Universities are very much constrained in terms of their choice of retrenchment strategy - they cannot fire tenured staff or close faculties in the way a business can shut down factories and lay off employees. A second problem is that the traditional model defines success purely in economic terms whereas universities can be effective only if they maintain morale and commitment. Thus, success involves a political component. Two Canadian universities faced with retrenchment are compared to show that, while the same cutback mechanisms were used, the process of implementing them was quite different. The result was similar economic outcomes but great variation in political terms. The article argues that the key to success is matching the content of the strategy with a process of implementation that is consistent with the particular university context. Thus, successful retrenchment strategy making may look different in different institutions.
\end{abstract}

\section{RÉSUMÉ}

Les problèmes de financement et d'insciption ont mené à une planification plus stratégique dans les universités. Le modèle traditionnel de processus de planification stratégique, qui est centré sur le contenu des stratégies et ne tient pas compte des autres éléments du processus d'élaboration, pose deux problèmes aux universités. Premièrement, les universités ont de sérieuses contraintes en ce qui touche leur choix de stratégie pour la réduction des dépenses. Contrairement au monde des affaires où la fermeture d'usines et la mise à pied du personnel est chose courante, les universités ne peuvent pas renvoyer le personnel permanent ou fermer des facultés. Deuxièmement, selon le modèle traditionnel le succès est basé uniquement sur des questions économiques; pour les universités cependant, il 
s'agit plutôt de maintenir le moral et de remplir une mission. Pour elles, le succès a donc une composante politique. La comparaison de deux universités canadiennes confrontées à des restrictions budgétaires a permis de montrer que bien $q u$ 'elles utilisent les mêmes mécanismes, leurs procédés respectifs d'implantation de ces mesures étaient fort différents. Il en a résulté des fins économiques semblables mais un grand écart sur le plan politique. Dans cet article, on essaie de prouver que la clé du succès est d' harmoniser le contenu de la stratégie avec un processus d' implantation qui respecte le contexte particulier d'une université. Et que, par conséquent, l'élaboration d'une stratégie de restriction budgétaire réussie peut varier d'une université à l'autre.

\section{INTRODUCTION}

Universities in many countries have recently had to deal with the problem of reduced funding. There remains considerable controversy, yet little empirical research, as to the best method of making cutbacks. Many writers have advocated "hard" decisions involving selective and targetted cuts (for example, Mayhew, 1979; Dube et al, 1983; Mingle, 1981; Heydinger, 1982). This preference for "surgery" rather than "shaving" reflects an attempt to impose professional management practices on universities which, it is believed, will improve their ability to cope with an increasingly hostile environment (Hardy, 1985, 1986). We would be ill-advised, however, to assume that the business model is appropriate for university administration until more research is conducted on how universities make cutbacks and whether they are successful. There are a number of reasons for exercising caution in the case of retrenchment strategy making.

Firstly, the business model tends to focus on the content of cutback strategies what should be cut. In the case of universities, however, the choice of strategy is limited. They do not have access to the same range of economic options as does a business in coping with restraint. Universities cannot fire tenured faculty, close faculties, or phase out programs in the way that a company can close factories and lay off workers. Second, the business model largely ignores the process of strategy making - how cutbacks are to be carried out. University presidents cannot impose cutbacks as the chief executive officer of a company might. Universities are professional bureaucracies (Mintzberg, 1979): power is decentralized in the hands of the professors; many different interest groups, both inside and outside the institution, influence decision making; performance cannot be easily measured; the diversity of departments makes comparisons difficult; decisions are influenced by political, collegial and garbage can processes, as much as by rational analysis (Hardy et al, 1983). Administrators have to consult the professoriate and put proposals before senate. Carefully formulated plans will be changed or abandoned if professorial support is not secured. Third, the conventional model of strategy making not only fails to take into account the factors that make universities different from business organizations; it also fails to acknowledge that not all 
STRATEGY MAK ING

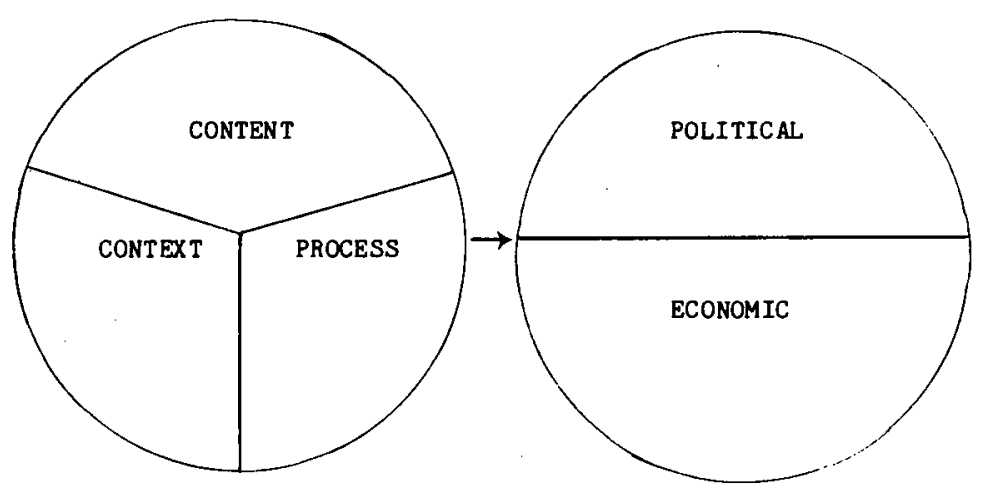

universities are the same (Blau, 1973). The particular institutional context must be taken into account - size, diversity, formal governance mechanisms, culture have implications for the cutback process. What may be an acceptable way of managing cutbacks in one university may be totally infeasible in another. Consequently, administrators must ask themselves where cutbacks are occuring if they are to fine tune their decisions to produce a strategy that is both workable and palatable in their particular institution.

There are, then, three fundamental components of strategy making - content, context and process (Pettigrew, 1984). Strategic choice is not just a simple of matter of finding the optimal solution to a clearly articulated problem; both the identification of the problem and the choice of solution is influenced by the context in which and process whereby decisions are taken. Thus, to fully understand strategy making we cannot confine our attention to what should be done; we must also address where the cutbacks are taking place and how they are to be carried out. Similarly administrators, if they are to effectively intervene in the strategy making process, must ask themselves the same questions.

A final reason why the conventional strategy making model might be ineffective is that it focusses almost exclusively on economic rationale which may be acceptable in the corporate world, but is less appropriate to higher education. Universities are not in the business of making money and, while they are currently under some pressure to become more efficient, they are also charged with the task of providing excellence in research and teaching. Excellence is not necessarily to be found in the healthiest balance sheet or in the introduction of new cost control methods; it is associated with the ability to recruit and retain talented and productive individuals (Pearson, 1986). This, in turn, will be related to the motivation and commitment of the professoriate. Successful retrenchment thus involves much more than economics, it also rests on political skills. The former 
relate to efficiency and effective resource allocation; while the latter refer to the ability to generate commitment and avoid conflict between interest groups (Warmsley \& Zald, 1973).

If we put these pieces together (diagram 1) we can see that it is the interplay of content, process and context that produces the economic and political outcomes which determine the success of the cutback exercise. This article examines these relationships with reference to a comparison of two Montreal universities which have suffered from restrictions in government funding in recent years - McGill University and the University of Montreal (UM). The study involved interviews with central administrators, deans, and department heads; a questionnaire was distributed to professors; and documentation was collected and analyzed [1].

\section{THE UNIVERSITIES}

McGill and UM are similar universities in terms of their structural characteristics (table 1). While the figures must be interpreted with care since different methods of calculation are often used, they do reflect two comparable institutions in terms of size and diversity. McGill is one of the oldest Canadian universities: it was established in 1821 with a bequest from James McGill. While it retains a private charter McGill is, for all intents and purposes, publicly funded. UM is a French-speaking institution which was originally founded in 1878, as part of Laval University. It received its own charter in 1920 and was a Roman Catholic institution until 1967, when a new charter made it a public university. Today, the two universities are much the same size, with a similar diversity of disciplines. Both have a number of professional schools, including medical and dental faculties and a heavy emphasis is put on research and graduate education. So, despite the linguistic differences, the two universities are not dissimilar.

\section{FUNDING RESTRICTIONS}

Funding restrictions in Quebec began during the late 1970s when increases in operating grants were less than agreed salary raises. In 1981, the government announced plans to reduce funding for the following three years. As a result, between 1979/80 and 1983/4, total university grants in Quebec were reduced by 13 per cent in constant dollars; while the percentage of Quebec's budget spent on universities decreased from 4.6 per cent to 3.5 per cent. Both universities were confronted with increases in revenue which were significantly less than inflation. The resulting financial pressure resulted in the reduction of staff at the same time as student numbers were increasing (table 2). While the figures are, obviously, not exactly the same, both universities have had to deal with a similar magnitude of cuts over the period 1980/1 to 1983/4. McGill has had to endure a greater reduction in its operating revenue but has been able to compensate with income from other sources, although increases in expenditure on faculties and services have not been much higher than at UM. Reductions in professorial staff and student increases have been similar. 
Using Content, Context, and Process to

69 Manage University Cutbacks

Table 1.

University Characteristios 1983/4 [A]

\begin{tabular}{lcc} 
& UM & McGill \\
\cline { 2 - 2 } \# Student & 29191 & 30526 \\
\# Graduate Students & 6766 & 5354 \\
\# Professors & 1481 & 1494 \\
\% Assistant Professors & 19 & 22 \\
\% Professors 40+ years & 70 & 70 \\
Nonteaching Staff [C] & 2497 & 2400 \\
Total expenses & $\$ 241 \mathrm{~m}$ & $\$ 246 \mathrm{~m}$ \\
Research as \% Total Budget & 14 & 23 \\
\% operating revenues provided by & 94 & 77 \\
Quebec & &
\end{tabular}

Faculties

Arts \& Science
Continuing Education
Dentistry
Education
Graduate Studies
Law
Medicine
Music
Nursing
Pharmacy
Planning
Mneology
Veterinary Science

Agriculture

Arts

Cont. Education [B]

Dentistry

Education

Engineering

Grad. Studies

Law

Management

Medicine

Music

Relig. Studies

Science

\begin{abstract}
[A] Numbers are approximate since universities use different methods of counting. Figures are derived from annual reports and information provided by the Planning office at McGill and the Bureau de Recherche Institutionelle at UM.

[B] Continuing Education exists but is not a faculty at McGill; Management and Engineering are carried out in affiliated schools at UM -- Ecole Hautes Etudes Commerciales and Ecole Polytechnic -- with separate budgets.

[C] UM figures are full time equivalents (FTEs)
\end{abstract}

\title{
DEALING WITH THE CUTBACKS
}

The two universities have chosen similar mechanisms for reducing expenditures. Since 80 per cent of the budget is tied up in salaries and tenure and job security protect the majority of employees, reducing posts through attrition has been the main cutback mechanism in both universities. Between 1979/80 and 1984/5 UM cut 425 nonacademic posts and 120 academic posts; while between 1978/9 and 1982/3 McGill cut 300 nonacademic posts and 140 academic posts. McGill has had some additional flexibility in freezing salaries since staff are nonunionized and 
Table 2 .

Changes at UM and McGill 1980/1-1983/4 (\$)

\begin{tabular}{lcc} 
& UM & McGill \\
\cline { 2 - 2 } Quebec operating grant [A] & +8 & +4 \\
Total Income & +12 & +25 \\
Nonresearch Income & +8 & +17 \\
Expenditure on Faculties \& Services & +9 & +14 \\
Total Expenditure & +13 & +26 \\
Nonresearch Expenditure & +9 & +19 \\
Accumulated Deficit [B] & $\$ 13 \mathrm{~m}$ & $\$ 7 \mathrm{~m}$ \\
\# Total teaching staff & -10 & -13 \\
\# Professors & -4 & -4 \\
\# Nonteaching Staff & -23 & -9 \\
\# Students & +9 & +6
\end{tabular}

[A] increases in dollars do not take into account inflation; increases should be measured against a $22 \%$ increase in the CPI during the same period.

[B] UM spent a $\$ 6 \mathrm{~m}$ surplus and incurred a $\$ 7 \mathrm{~m}$ deficit; McGill spent $\$ 7 \mathrm{~m}$ of its unrestricted endowment fund.

agreed to forego wage increases. Since 1977/8, $\$ 7.1$ million has been saved in this way. Both universities have temporarily relied on hiring freezes; tenure has not been broken and neither institution looks likely to introduce tenure quotas in the near future. Sabbatical policy is largely unchanged; early retirement has been used spasmodically; and contracts of some untenured faculty have not been renewed.

Government policies have prevented UM and McGill from raising tuition fees to increase revenue. Research funding has increased by 60 per cent at McGill and 52 per cent at UM, although this creates its own problems. Overhead costs are not funded by many of the key agencies and estimates suggest that every research dollar creates as much as one additional dollar in overhead. Both universities have introduced capital campaigns - McGill is in the process of raising $\$ 61$ million while UM recently raised $\$ 25$ million.

\section{DIFFERENCES IN PROCESS}

In response to similar financial constraints McGill and UM - comparable institutions structurally speaking - have chosen similar strategies to save and raise money. In effect, the content of the retrenchment strategies was much the same. 
The process each university employed to implement these cutbacks, however, was quite different.

At UM across-the-board cuts were implemented in 1981/2 because the government announcement concerning funding restrictions was not made until mid-year which left little time to plan anything else. Faculty budgets were cut by 3.5 per cent, services by 5.5 per cent, and administrative units by 2.5 per cent. During the following two years, however, differential cuts were made. "Productivity" formulae were developed by administrators to evaluate general teaching, graduate teaching and research. Resources were allocated on the basis of productivity - the more productive, the smaller the cut. In this way differential cuts of up to 11 per cent in 1982/3 and up to 7 per cent in 1983/4 were made (see Belanger \& Tremblay, 1982).

McGill did not use a special mechanism to implement cutbacks but relied on a funding formula which has been used to allocate resources for a number of years. The formula is based on student numbers - in very general terms, faculties and departments which increase students receive more money; those with fewer students receive less. The previous year's base budget is multiplied by the formula to take into account enrolment changes, and this amount is then normalized to equal the amount available to spend. In order to free up a small amount of discretionary money, budgets have been reduced by slightly more than the amount necessary to meet funding cuts. The difference goes into a fund (around 3 per cent of the budget), which is allocated on faculties in response to deans' demands and plans.

The two universities have, then, adopted different processes for implementing cutbacks. To understand why this is so we have to examine the context of the two institutions more carefully.

\section{DIFFERENCES IN CONTEXT}

While the two universities are structurally similar, the cultural dimensions of their contexts are quite different. One area where this is particularly clear is in their use of formal planning and quantitative analysis.

UM is a university in which quantitative studies are common. There have been numerous committees and reports on budgetary constraints. In 1981 there were two committees on priorities in teaching and research, and in administrative and service sectors. In 1982 a committee developed the productivity formula for 1982/3; while a second committee refined it for the following year; a study in 1983 examined the cost and benefits of closing a department; and in 1985 a working group on priorities engaged in a major comparative analysis of the research and teaching productivity in all disciplines against their counterparts in 11 major Canadian universities (Belanger \& Lacroix, 1986). In addition, each year the Office of Institutional Research puts out a variety of publications. All these reports are lengthy with a considerable emphasis on numbers and charts, for example, the most recent report consists of 463 pages of text and tables and an additional 249 pages in an appendix. 
The number of reports and committees reflects a substantial amount of analysis which is used by administrators to legitimize resource allocation decisions. For example, the decision not to cut any units was explained with reference to the study.

It would be difficult to cut a complete unit... We've done some analysis and in all cases we cannot cut expenditures enough to compensate for the loss of the grant (administrator).

The most recent study on priorities was a highly complex and quantitative exercise. It was viewed by deans as an essential step in planning priorities and resource allocation for the future.

The last phase is the comparison with other institutions and getting faculties to identify the areas they want to preserve. Maybe then we could make a few comparisons and a few choices (dean).

Thus, formal planning and quantitative data are highly visible at UM. This has not been the case at McGill where there have only been two committees struck to explore the cutbacks - a taskforce in 1981; another in 1985. Both have produced reports which are brief (50 and 28 pages) with few figures, and which are characterized by general policy statements on how cutbacks should be handled (for example, the position on deficit financing, or salary freezes) rather than intensive quantitative analysis.

Concomitant with this quantitative approach at $\mathrm{UM}$ was a relatively centralized decision making structure. Questionnaire results indicated that UM professors saw the central administration playing a far greater role in deciding on cutbacks than McGill professors (table 5). Central administrators at UM had made an apparent move to decentralize resource allocation by giving deans a global budget, but did so at the same time as cutbacks removed any significant decision making power.

Some cynics said: now they don't have any money left, they give the power to the deans; when they had money left they kept the money to themselves .... I am one of those cynics (assistant dean).

Formal planning played a much less prominent role at McGill (Thompson, 1977). Deans, for example, were particularly suspicious of it.

I see planning as an expanding bureaucracy, of very little assistance to me but capable of creating several structures of bullshit that I have to cope with (dean).

The numbers are nice if you want to justify something more or less after the fact. The real academic planning has somehow to be based on a lot of subjective factors... . That kind of planning does not make much use of the type of resources the planning office has - statistical data (dean).

The technocratic approach has been far less evident at McGill and administrators have been reluctant to use overtly differential mechanisms which might lead to conflict between departments and faculties, particularly at a time of scarce resources. 

How important do you feel the following were in deciding on the
ways of making cutbacks?

$\frac{\text { Aggregated Figures }}{U M}$

Our strategy all along has been to try to manage with diminishing resources in a way that reinforces some parts of the university but not others, and at the same time not dramatically disturb morale... . You constantly ask yourself whether you can accomplish the goal of trimming without throwing the campus into a state of turmoil (central administrator).

The formula has been seen as a way of minimizing conflict since it has the appearance of objectivity and avoids any radical reallocation of resources.

The formula is hoped to satisfy everyone, which means it satisfies no one, but you hope it satisfies no one about equally (member of the board of govenors).

While the discretionary fund has to be shared between the deans, they "never compete in an open forum" and the private negotiations are "kept civil" (dean).

Decision making is far more decentralized (Thompson, 1977) through global budgets at the level of dean or, in the case of the larger departmentalized faculties, department heads. This has resulted in perceptions of far more involvement in cutback decision making by department heads and individuals, and much less by central administrators (table 5).

This context has been said to approximate the collegial model commonly associated with universities (Thompson, 1977), which extends both laterally and vertically. For example, the deans perceived themselves as a highly cohesive group.

I don't think there's a sense of guarding territory much here there's a lot of collegiality, a lot of sense that we're all in this together and that we can help each other and learn from each other (dean);

while those at UM expressed more separateness.

The deans have always been competitive in a gentlemanly way. No one bangs the table and says I want more money .... [but] everyone has his own territory and doesn't enter into anyone else's (dean at UM).

Collegiality also characterizes the relations between administration and staff which were described as extremely good by both sides. Unlike UM, McGill is not 
Table 3.

Changes in Budget, Student and Staff Allocation 1980/1-1983/4

\begin{tabular}{|c|c|c|c|c|c|c|}
\hline \multirow[b]{2}{*}{ UM: Faculty [B] } & \multicolumn{2}{|c|}{$\begin{array}{l}\text { Proportion of } \\
\text { Budget }(q)\end{array}$} & \multicolumn{2}{|c|}{$\begin{array}{l}\text { Proportion of } \\
\text { Students }(\not) \text { [A] }\end{array}$} & \multicolumn{2}{|c|}{$\begin{array}{l}\text { Proportion of } \\
\text { Staff }(q)\end{array}$} \\
\hline & $1980 / 1$ & $1983 / 4$ & $1980 / 1$ & $1983 / 4$ & $1980 / 1$ & $1983 / 4$ \\
\hline Arts \& Science & 35 & 36 & 38 & 39 & 34 & 34 \\
\hline Dentistry & 5 & 5 & 2 & 2 & 4 & 4 \\
\hline Education & 7 & 6 & 2 & 1 & 10 & 7 \\
\hline Law & 3 & 3 & 6 & 5 & 3 & 3 \\
\hline Medicine & 25 & 25 & 15 & 15 & 20 & 22 \\
\hline Music & 2 & 2 & 2 & 2 & 3 & 3 \\
\hline Nursing & 1 & 1 & 1 & 1 & 2 & 2 \\
\hline Pharmacy & 1 & 1 & 2 & 2 & 1 & 1 \\
\hline Planning & 3 & 3 & 3 & 3 & 3 & 3 \\
\hline Theology & 1 & 1 & 2 & 2 & 1 & 1 \\
\hline Veterinary Science & 5 & 5 & 2 & 2 & 2 & 2 \\
\hline \multicolumn{7}{|l|}{ McGill: Faculty } \\
\hline Agriculture & 6 & 6 & 5 & 5 & 6 & 6 \\
\hline Arts & 16 & 16 & 22 & 21 & 19 & 19 \\
\hline Dentistry & 2 & 2 & 1 & 1 & 2 & 2 \\
\hline Education & 9 & 9 & 9 & 8 & 12 & 10 \\
\hline Engineering & 11 & 11 & 11 & 11 & 11 & 11 \\
\hline Law & 2 & 3 & 3 & 3 & 2 & 3 \\
\hline Management & 5 & 5 & 8 & 8 & 5 & 4 \\
\hline Medicine & 21 & 21 & 14 & 14 & 16 & 18 \\
\hline Music & 3 & 3 & 2 & 2 & 3 & 4 \\
\hline Religious Studies & 1 & 1 & 1 & 1 & 1 & 1 \\
\hline Science & 18 & 18 & 16 & 17 & 20 & 19 \\
\hline
\end{tabular}

[A] UM and McGill calculate student credits slightly differently.

[B] Graduate Faculty and Continuing Education have not been included.

unionized. Moreover, staff and faculty associations agreed to forego wage increases to help McGill deal with cutbacks, which association leaders considered to be a reflection of the loyalty to the institution.

There's not much antagonism between MAUT [McGill Association of University Teachers] and administration. MAUT believes decisions made by the board are fair (MAUT member).

\section{The Outcomes}

While the two universities have made similar choices concerning the content of their retrenchment strategies, strategy making has differed in the two institutions because of significant variations in process and context. What has been the result of these differences - in both economic and political terms?

When considering economic outcomes we must focus on the allocation of resources. In terms of redistributing funds between faculties, the two universities show similar results (table 3 ) - there was no radical reallocation of resources in either university. 
Table 4 .

Sources of Revenues ( $q$ )

\begin{tabular}{|c|c|c|c|c|}
\hline & \multicolumn{2}{|c|}{ UM } & \multicolumn{2}{|c|}{ MeGill } \\
\hline & $1980 / 1$ & $1983 / 4$ & $1980 / 1$ & $1983 / 4$ \\
\hline Fees & 5 & 5 & 6 & 8 \\
\hline Quebec Grant & 77 & 74 & 57 & 49 \\
\hline Research & 10 & 14 & 19 & 23 \\
\hline Private Income/gifts & - & - & 3 & 4 \\
\hline Other & 8 & 7 & 15 & 16 \\
\hline
\end{tabular}

The university has not seen fit to allocate monies to areas with growth potential; nor to clear house in some areas (dean at McGill).

We did not make choices even with the criteria we had designed. It was not a formula conducive to choices. (administrator at UM).

The only exception seems to be the Faculty of Law which has benefitted in both universities - by reducing its student share while maintaining its budget at UM, and by holding student share while increasing its budget at McGill.

The similarities might seem surprising considering that UM's formula accentuated differentiation while McGill's obscured it. It is the result of three main factors. Firstly, UM's assessed differential cuts on a departmental basis but awarded global budgets to deans so differences have tended to offset each other. Secondly, McGill's discretionary fund injected a differential element into the process. Third, attrition was the main cutback mechanism and since both universities are old, large and with similar faculties, one would expect a similar demographic profile. Thus, savings were made in similar areas - those populated with older professors who took retirement.

As a result of their expenditure reduction and revenue raising strategies both universities have reduced their dependency on government funding and increased research revenue. McGill has had slightly more success in diversifying its sources of income (table 4) with the help of the interest from a large endowment (\$163 million in 1983/4).

Neither university has balanced its books. UM used up a $\$ 6$ million surplus and accumulated a $\$ 7$ million deficit between $1980 / 1$ and 1983/4. McGill used $\$ 7$ million of the unrestricted portion of its endowment to fund operating deficits during the same period. This study is not qualified to say whether the smaller amount reflects better day-to-day management at McGill or the long-standing advantage of catering to the wealthy anglophone segment of Montreal with its tradition of university donations. Certainly the latter provides a buffer which was not available to UM.

If the economic results look much the same, the political differences are clearer. While professors at both institutions rated the damage done by the cuts on their morale, autonomy, collegiality, teaching, research and program quality in comparable terms (table 6), those at UM were more discontented in general. They felt 
Table 6. [2]

\begin{tabular}{|c|c|c|c|}
\hline & $\begin{array}{l}\text { What has been the effect } \\
\qquad \begin{array}{l}1 \text { - very negative } \\
2 \text { - somewhat negative } \\
3 \text { - no effect } \\
4 \text { - somewhat positive } \\
5 \text { - very positive }\end{array}\end{array}$ & & $e$ \\
\hline & & $\mathrm{UM}$ & McGill \\
\hline (i) & your morale & 2.1 & $(2.1)$ \\
\hline (ii) & departmental morale & 1.7 & $(2.0)$ \\
\hline (iii) & individual autonomy & 2.5 & $(2.6)$ \\
\hline (iv) & collegiality & 2.4 & $(2.5)$ \\
\hline (v) & your teaching & 2.4 & $(2.5)$ \\
\hline$(v i)$ & your research & 2.2 & $(2.3)$ \\
\hline (vii) & quality of programs & 1.9 & $(2.0)$ \\
\hline
\end{tabular}

that departmental morale had suffered more from cutbacks, and were less satisfied with faculty participation in the determination of policy, curriculum, faculty appointments, promotion and tenure, budgets and plans. Confidence in leadership was lower, as was commitment to the university and faculty. They attributed more blame to their administrators for the cuts and were less satisfied with their ability to handle them. Cuts at UM were perceived as less fair, more political, and less objectively good for the institution than at McGill (see following tables).

The interviews reflected similar views. The differential cuts at UM evoked considerable criticism from deans.

[Central administrators] were criticized because they were making a judgement of the faculties... . They were ranking the faculties on research and many deans didn't like that. The ratios [in the formulae] placed the faculties in a position where they had to compare on the same basis (assistant dean).

As a result, the leadership in general met with increasing criticism.

With the management of this university, you have a hard time seeing where they are going. I'm not sure they know where they are going either (dean).

At McGill, in contrast, both interviews and questionnaires indicated much stronger support for the central administration.

\section{INTEGRATING CONTENT, CONTEXT AND PROCESS}

If we evaluate the outcomes of retrenchment at the two universities, it would seem that the economic results are much the same, undoubtedly the result of similar 


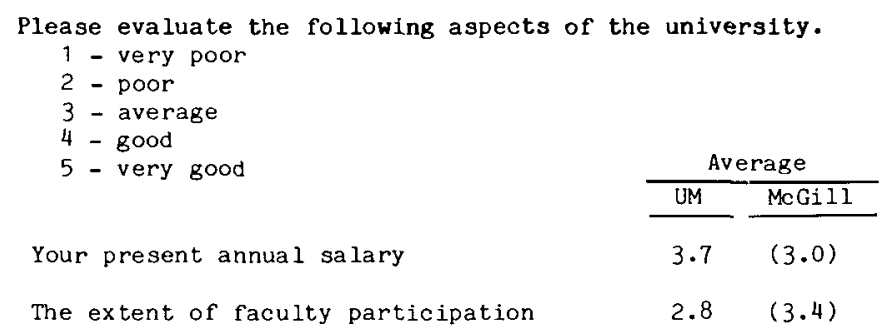

(ii) The extent of faculty participation $2.8 \quad$ (3.4) in the determination of academic policies and procedures

Your general confidence in the leadership 2.8 of your faculty

cutback mechanisms. McGill's slightly superior performance in diversifying its funding and containing its deficit did not derive from a different choice of retrenchment strategy but was due, at least in part, to the flexibility provided by its endowment income.

Politically speaking McGill would appear to have been more successful despite similar cuts and a similar assessement of those cuts by the two groups of professors, those at McGill were less critical of both the process of cutback and the general management of the institution. This can be explained by the differences in context and process. At McGill the collegial context created a situation which was conducive to the successful management of cutbacks - the faculty are loyal and nonunionized, and the leadership has high credibility. The process used to implement the cutbacks - decentralized and ostensibly "fair" - reinforced that collegial culture. At UM, decision making has been more centralized and technocratic, and central administration suffered from credibility problems, both of which helped produce a context far less amenable to successful cutback management. The cutback process did little to improve the situation: it was perceived as centralized since the committees which devised the formulae were predominantly administrative; the quantitative analysis was criticized as lacking sufficient rigour; and the differential approach caused conflict. The result was that the central administration received a considerable amount of blame compared with McGill. 
Table 8. [2]

How would you rate your commitment to the following.

1 - low

5 - high

$\frac{\text { Average }}{\mathrm{UM} \text { MoGill }}$

(i) The university

$3.4(4.1)$

(ii) Your faculty $3.6 \quad 3 \quad(4.0)$

(iii) Your department $\quad 4.4 \quad$ (4.4)

(iv) Your job $4.6 \quad 4$ (4.8)

Table 9. [2]

Please indicate how satisfied you are with the degree of influence faculty members have over the following.

1 - very dissatisfied

2 - fairly dissatisfied

3 - neutral

4 - fairly satisfied

5 - very satisfied

(i) Curriculum

$\frac{\text { Average }}{3.4} \frac{\text { MCGill }}{(4.0)}$

(ii)

Faculty appointments

$2.9 \quad(3.5)$

(iii)

Selection of department heads

$3.4 \quad(3.5)$

(iv)

Promotion \& tenure

$2.9 \quad(3.4)$

(v)

Faculty budget

$2.0 \quad(2.4)$

(vi)

University budget

$1.8 \quad(2.1)$

(vii) Long range university plans

$1.9 \quad(2.4)$

(viii)

External/public relations

$2.4 \quad(2.8)$

\section{SUMMARY AND CONCLUSIONS}

The comparison of the two universities shows that successful retrenchment is not purely an economic issue, defined solely in terms of the ability to balance the budget. A university may have black ink on the bottom line but be losing its best professors, students and administrators. Success also involves a political component - the ability to sustain high levels of morale and commitment - which is influenced by content, process and context (see diagram 2). Effective administrators will be those who understand the relationships between these components, and who can develop the political skills necessary to manage them. 
To what extent do you believe the following to be responsible for the current budgetary constraints?

\begin{tabular}{llcc} 
& & \multicolumn{2}{c}{ Aggregated Figures } \\
\cline { 2 - 2 } (i) & general economy & $38 \%$ & $(40 \%)$ \\
(ii) & government & $40 \%$ & $(46 \%)$ \\
(iii) & university administration & $15 \%$ & $(10 \%)$ \\
(iv) & faculty administration & $6 \%$ & $(1 \%)$ \\
(v) & other & $1 \%$ & $(2 \%)$ \\
\hline
\end{tabular}

Table 11. [2]

How fairly do you feel the budget cuts have been allocated between faculties?

$\begin{array}{llcc}\text { (i) } & \text { very fairly } & 3 \% & (6 \%) \\ \text { (ii) } & \text { somewhat fairly } & 32 \% & (41 \%) \\ \text { (iii) } & \text { not very fairly } & 34 \% & (25 \%) \\ \text { (iv) } & \text { not fairly at all } & 16 \% & (15 \%) \\ \text { (v) } & \text { no opinion } & 15 \% & (13 \%)\end{array}$

Administrators must learn to identify the key characteristics of their context and the choices available to them regarding content and process i.e. what is to be cut and how it is to be handled. Since the choices concerning content are often limited in universities, the focus may be on matching the process to the context. We should not, therefore, be surprised to find that successful retrenchment looks different in different institutions: the technocratic university may be more centralized if it can develop acceptable methodologies for resource allocation; while the collegial institution will rely on more qualitative studies and bottom-up change. For example, at UM the recent study on priorities had much more legitimacy than the previous formulae - it was methodologically more rigorous than earlier studies and was not commissioned by the administration - possibly providing an acceptable and workable basis on which to reallocate resources. The appointment of a new rector appeared to enhance the credibility of management and increase support for centralized decisions concerning the funding of priorities. In effect, the change in 
context resulting from new leadership may have opened a window of opportunity to allow the administration to use the most recent quantitative analysis to take some selective and "tough" decisions.

McGill, on the other hand, will probably continue to adopt a decentralized approach to retrenchment, although this may become increasingly difficult. So far, the university has had sufficient financial flexibility to offset at least some of the cutbacks, but there is no longer any unrestricted endowment left and staff have expressed a reluctance for further pay freezes. Should future restrictions necessitate selective decisions, the university may find itself without the tools to make such decisions. Even if it can make these choices, the decentralized nature of the university will make their implementation extremely difficult. Finally, any attempt to centralize decision making in an attempt to solve these problems will compromise the collegiality on which McGill prides itself. In other words, if funding restrictions intensify, McGill may find that its context becomes increasingly constraining and its ability to protect commitment and morale more difficult.

This article has illustrated some of the interactions within the strategy making process by focussing primarily on the link between the cultural aspects of context, process, and political outcomes. It cannot, however, answer all the questions raised by such a model. It is, for example, impossible within the framework of this research to quantify the differential effects of the three components on the two outcomes. The results of discontent with the process of cutback at UM cannot be isolated from dissatisfaction with the leadership in general. Similarly, the research cannot clarify why or how McGill came to approximate the collegial model while UM has adopted a more quantitative and technocratic culture. These contextual differences are the result of decisions, individuals and governance structures that have evolved over many years. In facing such complexity, the researcher is in a similar position as the practitioner who has to deal with an existing situation which is difficult to change, particularly in the short term. An administrator has to juggle the constraints of content, context and process to arrive at a solution which is both palatable and feasible in the particular institution.

The article hints at other relationships. There appears to be a link between economic variables - McGill's endowment represents an economic aspect of its context which helped produce a slightly healthier balance sheet. UM and McGill are similar in size and diversity; would universities with other structural characteristics act differently? Do other types of university culture exist and what are their implications for retrenchment and strategy making? Are there external components of context - do provincial, state or national differences have an effect? Context would appear, then, to be a complex concept, involving economic, structural, cultural, internal and external factors, which requires further analysis. Other questions remain unanswered. Do the different components of the strategy making process influence each other? Does, for example, decentralized decision making preclude highly selective cuts? Will the choice of certain strategies or processes of implementation change the culture? Will continued funding problems 
Diagram 2.

Strategy Making and outcomes at McGill

STRATEGY MAKING

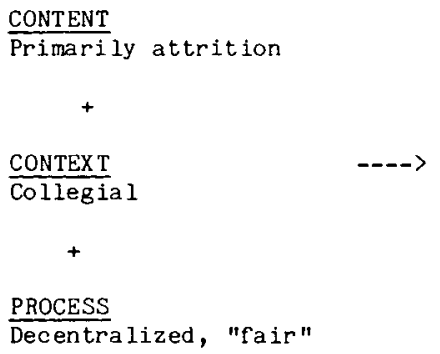

\section{OUTCOMES}

POLITICAL

Relatively high levels of commitment and satisfaction

ECONOMIC

Deficit, some

diversification of

revenue, no

reallocation

\section{Strategy Making and Outcomes at UM}

\section{STRATEGY MAK ING}

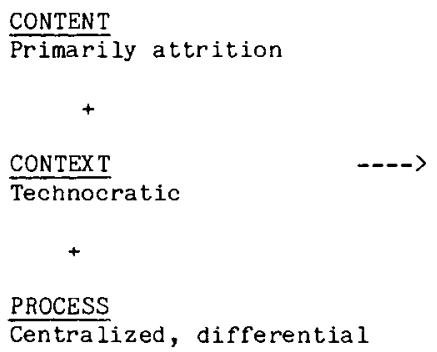

\section{OUTCOMES}

POLITICAL

Lower levels

of commitment and

satisfaction

ECONOMIC

Deficit, some

diversification of

revenue, no

reallocation

make the economic side of the equation more crucial or will political resistance make economic solutions more difficult to impose? While some relationships have been suggested further research, which explores the links more systematically and in a larger sample, is necessary to answer these questions fully.

\section{NOTES}

1. Interviews were carried out with all deans or their representatives and central administrators. All except two central administrators at UM agreed to be interviewed. Interviews were also carried out with a selection of department heads chosen from some of the larger faculties to give the researcher an insight into the "lower" levels. In total more than 200 interviews were carried out. They were semi-structured, designed to cover key issues but open-ended enough to allow unforeseen issues to be pursued. It should be noted that the quotations in the text are taken from the interviews, which 
were recorded. These quotes are used to illustrate patterns in a particular group of interviewees. For example, a quotation from a dean reflects similar feelings amongst the deans as a group. Questionnaires were distributed to professors. At McGill all full-time, tenure stream professors received one and the response rate was $33 \%$. At UM, to avoid a conflict with other research and a similar questionnaire, every second name, by department, was sent a questionnaire and the response rate was $27 \%$. Documentation which is cited here, for example, the task force reports, the studies for the formulae, were collected and analyzed to support (or refute) the information provided by the interviews.

2. The questions presented here are taken from the questionnaire. They represent the relevant questions; other questions in the questionnaire did not pertain to the issues discussed here and so are not shown.

\section{BIBLIOGRAPHY}

Belanger, C. \& Tremblay, L., "A Methodological Approach to Selective Cutbacks", Canadian Journal of Higher Education, 12(3), 25-36, 1982.

Belanger, C. \& Lacroix, R., "Measuring the Effectiveness of Research Grant Getting", Canadian Journal of Higher Education, 16(1), 25-40, 1986.

Blau, P.M., The Organization of Academic Work, New York, Wiley: 1973.

Dube, C. S. \& Brown, A. W., "Strategic Assessment: A Rational Response to University Cutbacks", Long Range Planning, 16, 105-113, 1983.

Hardy, C., Langley, A., Mintzberg, H. \& Rose, J., "Strategy Formation in the University Setting", The Review of Education, 6(4), 407-33, 1983.

Hardy, C., Universities and Change: Managing Strategic Change, paper presented at the European Forum of the Association of Institutional Research, Copenhagen, 1985.

Hardy, C., Universities and Decline: Operating, Strategic and Political Turnaround, paper presented at the Annual Conference of the Association for the Study of Higher Education, San Antonio, 1986.

Heydinger, R. B., Using Program Priorities to Make Retrenchment Decisions: The Case of the University of Minnesota, Southern Regional Education Board, 1982.

Mayhew, L. B., Surviving the Eighties, San Francisco: Jossey Bass, 1979.

Mingle, J. R., Challenges of Retrenchment, San Francisco: Jossey Bass, 1981.

Mintzberg, H., The Structuring of Organizations, Englewood Cliffs, NJ: Prentice Hall, 1979.

Pettigrew, A. M., Culture and Politics in Strategic Decision Making and Change, paper presented at the Symposium on Strategic Decision Making in Complex Organizations, Columbia University, New York, December 1984.

Pearson, M., Managing for Excellence or Walk the Jarratt Way, paper presented at the 8th European Forum of the Association of Institutional Research, Loughborough, UK, September, 1986.

Thompson, D. C., "The State of Planning at McGill", McGill Journal of Education, 12(1), 42-56, 1977.

Warmsley, G. L. \& Zald, M. N., "The Political Economy of Public Organizations", Public Administration Review, 33, 62-73, 1973. 